\title{
The relative sensitivity of sperm, eggs and embryos to copper in the blue mussel (Mytilus trossulus)
}

\author{
J.L. Fitzpatrick $^{\mathrm{a}, \mathrm{c}, *}$, S. Nadella ${ }^{\mathrm{a}, \mathrm{c}}$, C. Bucking ${ }^{\mathrm{a}, \mathrm{c}}$, S. Balshine ${ }^{\mathrm{b}}$, C.M. Wood ${ }^{\mathrm{a}, \mathrm{c}}$ \\ ${ }^{a}$ Department of Biology, McMaster University, 1280 Main St. West, Hamilton, Ontario, Canada L8S 4K1 \\ b Animal Behaviour Group, Department of Psychology, Neuroscience and Behaviour, McMaster University, \\ 1280 Main St. West, Hamilton, Ontario, Canada L8S 4 K1 \\ ${ }^{\mathrm{c}}$ Bamfield Marine Sciences Centre, Bamfield, British Columbia, Canada
}

Received 5 December 2007; received in revised form 23 January 2008; accepted 24 January 2008 Available online 5 February 2008

\begin{abstract}
Copper, an essential element, is toxic at elevated concentrations, and as a result of anthropogenic activities is becoming increasingly prevalent in marine environments. In this study, we examined the effects of copper on early life stages of the blue mussel, Mytilus trossulus. We assessed the impacts of increasing copper concentrations on embryo development, egg viability, sperm fertilization capacity and, in particular, on sperm swimming speed using computer-assisted sperm analysis. Sensitivity to copper followed the pattern: embryos $>$ sperm $>$ eggs. A dramatic increase in abnormal embryo development was observed following exposure to copper concentrations exceeding $10 \mu \mathrm{g} / \mathrm{L}$. Sperm swimming speeds decreased significantly when exposed to $100 \mu \mathrm{g} / \mathrm{L}$ of copper, but lower doses did not influence sperm swimming speed. Copper exposure (at any tested concentration) did not affect sperm flagellum length, or alter egg viability. Based on our results, we suggest that exposure of sperm to copper may interfere with mitochondrial activity, which reduces sperm swimming speed during the extended duration of sperm motility in blue mussel.
\end{abstract}

(C) 2008 Elsevier Inc. All rights reserved.

Keywords: Ecotoxicology; Fertilization; Sperm; Eggs; Spermiotoxicity; Computer-assisted sperm analysis; Development

\section{Introduction}

Anthropogenic activities, such as the release of industrial effluent and the growing use of copper as an antifoulant (Apte and Day, 1998; Paulson et al., 1989), have resulted in copper becoming increasingly prevalent in coastal ecosystems. Natural copper concentrations in marine environments are typically $<5 \mu \mathrm{g} / \mathrm{L}$ (Soegianto et al., 1999; Hall and Anderson, 1999; Davenport and Redpath, 1984), but in polluted areas, copper levels can be orders of magnitude higher than natural levels, reaching concentrations of $>50 \mu \mathrm{g} / \mathrm{L}$ in heavily-polluted

\footnotetext{
* Corresponding author. Department of Biology, McMaster University, 1280 Main St. West, Hamilton, Ontario, Canada L8S 4K1. Tel.: +1 905525 9140x23237; fax: +19055296225.

E-mail address: fitzpaj1@mcmaster.ca (J.L. Fitzpatrick).
}

harbours (Haynes and Loong, 2002; Soegianto et al., 1999). The increasing copper concentrations in marine ecosystems are of particular concern because, although copper is a naturallyoccurring trace element that is essential for some metabolic processes, it can be toxic to marine organisms at elevated concentrations (White and Rainbow, 1985; Viarengo, 1989). A comprehensive examination of the potential impacts of copper toxicity on a variety of life stages of various marine biota can assist in informing regulatory decisions regarding acceptable water quality in the marine environment.

The early life stages of marine invertebrates are usually more susceptible to environmental toxicants than are the adult forms (see review by His et al., 1999). Copper exposure has been demonstrated to reduce fertilization success, larval development and attachment, impair embryogenesis, and alter enzymatic activity (Katranitsas et al., 2003; Xie et al., 2005; Bellas et al., 2001; Bellas et al., 2003; Bellas et al., 2004; 
Novelli et al., 2003; Fernandez and Beiras, 2001; ReicheltBrushett and Harrison, 2005; Ringwood, 1992; Dinnel et al., 1989). However, despite the extensive documentation of copper's adverse effects on early developmental stages, few studies have examined precisely how copper (or indeed any metal) decreases fertilization success by assessing how metals influence gamete function and morphology (see Earnshaw et al., 1986; Au et al., 2000, 2001a,b). Typically, in spermiotoxicity tests, metal toxicity is assessed by exposing sperm to the toxic agent for a short time period, then adding exposed sperm to eggs to assess fertilization success and allowing embryos to develop in polluted water. In echinoderms (i.e., sea urchins and sand dollars), bivalves and ascidians, such shortterm exposure of sperm to a variety of metals, including copper, has been demonstrated to reduce fertilization success (Novelli et al., 2003; Reichelt-Brushett and Harrison, 2005; Ringwood, 1992; Dinnel et al., 1989; Au et al., 2001a; Pagano et al., 1982; Bowen and Engel, 1996; Eyster and Morse, 1984; Ringwood, 1992; Bellas et al., 2004; but see Bellas et al., 2001). However, because fertilization trials in spermiotoxicity tests are performed with sperm that are swimming in metal-polluted water, this factor may also influence embryo development. Therefore it is not clear whether the reduced fertilization rates observed in these tests are the result of impaired sperm function or due to exposure of the developing embryos to metals.

Blue mussels (Mytilus trossulus), which are semi-sessile, filter-feeding marine bivalves found in all temperate and polar waters worldwide, were used in this study because ambient water quality guidelines are often based on toxicity tests with early life stages of blue mussels (US EPA, 1995a, summarized by Arnold, 2004; Arnold et al., 2005). Furthermore, there is ecological relevance in using this species as seasonal increases in copper concentrations (in spring and summer; Alliot and Frenet-Piron, 1990) often coincide with blue mussel gametogenesis (spring) and spawning (summer) (Thompson, 1984). Ripe male and female mussels release gametes through their exhalent siphon directly into the water column, where fertilization takes place (Thompson, 1984; Thorarinsdottir and Gunnarsson, 2003). Therefore, copper may influence recruitment by impairing sperm function (Earnshaw et al., 1986) and by disrupting embryogenesis (see references above). Current copper water quality guidelines are based on 48-h EC50 embryo-larval development chronic toxicity tests, in which developing embryos are exposed to a toxicant and effects are measured after 48-h exposure (US EPA, 1995a, summarized by Arnold, 2004; Arnold et al., 2005). Consequently, efforts aimed at improving environmental regulations focus solely on embryo survival, rather than examining the effects of toxicants on several early life stages.

Our study had two main objectives. First, we investigated whether or not the decreased fertilization success of blue mussels reported in other copper exposure studies was a result of decreased gamete function. Second, because it is unlikely that copper has effects on only one life stage, we examined effects at multiple early life stages, to better understand the adverse effects of copper exposure to blue mussels.

\section{Materials and methods}

\subsection{Study Species}

Between June 20-July 6, 2006, ripe blue mussels ( $M$. trossulus) were collected from natural intertidal populations in a pristine area, the Broken Island Group, near Bamfield, British Columbia $(48.45 \mathrm{~N}, 125.10 \mathrm{~W})$. Adults were cleaned, separated and transferred to $11-13{ }^{\circ} \mathrm{C}$ aerated, flowing seawater baths where they were held for up to $24 \mathrm{~h}$ prior to experimental treatment. Adults were then placed in a $10 \mathrm{~L}$ seawater bath (1520 adults/bath) maintained at $22-25^{\circ} \mathrm{C}$, constituting a thermal shock, which induced spawning. Adult gender cannot be determined externally; therefore, gender could only be determined subsequent to gamete release. Once gamete release was observed, the mussels were placed in isolated $250 \mathrm{~mL}$ beakers, on ice, containing filtered seawater (water volume varied by experiment) where the gametes were released into the water column. Adults were only used if they continued to release gametes after transfer to the beaker.

\subsection{Copper solutions and chemical analyses}

Copper solutions were prepared from a copper chloride $\left(\mathrm{CuCl}_{2}\right.$; Sigma-Aldrich) stock solution, using $0.20 \mu \mathrm{m}$-filtered seawater, serially diluted to make six copper solutions (nominally, 0.32, 1.0, 3.2, 10.0, 32.0, and $100.0 \mu \mathrm{g} / \mathrm{L}$ copper above the seawater background). In all experiments, gametes (both eggs and sperm) or developing embryos were exposed to these six copper solutions, as well as a control solution of filtered seawater.

Copper in seawater was analyzed based on methods modified from those described in Toyota et al. (1982). Briefly, $1 \mu 1$ of $10 \mathrm{mg} / \mathrm{mL}$ lanthanum oxide, $7.5 \mu 1$ of $1 \mathrm{M}$ sodium carbonate, and $7.5 \mu 1$ of a $1 \mathrm{~N}$ nitric acid were added to $1 \mathrm{~mL}$ of seawater. The solutions were placed in an $80{ }^{\circ} \mathrm{C}$ heat bath for $30 \mathrm{~min}$, forming a precipitate, then centrifuged at $3000 \mathrm{G}$ for $15 \mathrm{~min}$. The supernatant was decanted and the precipitates were dissolved in $1 \mathrm{~mL} 1 \mathrm{~N}$ nitric acid. Copper concentrations were determined from this solution using a graphite furnace atomic absorption spectroscopy (GFAAS; Varian SpectrAA-220 with graphite tube atomizer [GTA-110], Mulgrave, Australia). Fisher Scientific calibration standards were used for every run. The method detection limit was $0.2 \mu \mathrm{g} / \mathrm{l}$ and copper recovery was $\pm 10 \%$, as determined from the Analytical Reference Material TM15 (Environment Canada, National Water Research Institute). Copper concentrations were determined for the seawater and six copper exposure solutions used in this experiment (Exposure Concentrations, Table 1).

\subsection{Experiment 1: Effects of copper on sperm motility and fertilization success}

Following sperm release, males $(n=11)$ were placed in individual beakers (on ice) containing $70 \mathrm{~mL}$ of filtered seawater. They were left undisturbed for $3 \mathrm{~min}$, as sperm release 
Table 1

Copper concentrations (in $\mu \mathrm{g} / \mathrm{l}$ ) determined for exposure solutions at each of the nominal copper concentrations used in experiments during this study

\begin{tabular}{lc}
\hline Nominal concentration & Exposure concentrations (measured) \\
\hline 0 (control sea water) & $1.47 \pm 0.12$ \\
0.32 & $1.15 \pm 0.12$ \\
1.0 & $2.37 \pm 0.31$ \\
3.2 & $4.63 \pm 0.61$ \\
10 & $11.67 \pm 0.29$ \\
32 & $27.40 \pm 0.0$ \\
100 & $71.00 \pm 6.90$ \\
\hline
\end{tabular}

All data are presented as mean \pm standard error $(\mathrm{SE})(n=4)$.

continued, and were then removed from the beaker, leaving a $70 \mathrm{~mL}$ sperm/water mixture. Sperm concentration varied among males as some males released more sperm than others. As sperm concentration influences fertilization success (e.g. Hollows et al., 2007), we controlled for sperm density within each male by adding a homogenized mixture of sperm from a single male to a homogenized mixture of eggs across all treatments, thereby maintaining a roughly equal sperm:egg ratio in all treatments for each male. Thus, by using a repeated measures design we ensured that any observed effects are due to the effects of copper, rather than resulting from variation in sperm concentrations. The sperm/water mixture was homogenized by gently stirring, and $9 \mathrm{~mL}$ from each male's beaker was added to each of seven $15 \mathrm{~mL}$ plastic scintillation vials (on ice), representing the seawater control and the six copper solutions. Immediately after the sperm/water mixture was added to the scintillation vials, $1 \mathrm{~mL}$ of filtered seawater was added to the control while a $1 \mathrm{~mL}$ copper solution, at a concentration 10 times higher than the desired concentration, was added to each of the six copper treatments $(9 \mathrm{~mL})$, yielding the appropriate concentration.

After copper was added to the sample, sperm motility was recorded by placing a $60 \mu \mathrm{L}$ subsample from the scintillation vial on a 1-mm deep welled microscope slide, with a cover slip covering half of the depression (see Liley et al., 2002 for similar methods). Videos of sperm motility were captured at 60 frames/ s using a PixeLINK Megapixel PL-A662 digital video camera (PixeLINK, Ottawa, Ontario, Canada) mounted on a Leica DME light microscope (Leica Microsystems Inc., Buffalo, New York, USA), with a phase contrast filter in place, at $200 \mathrm{X}$ magnification. Images were recorded using PixeLink PL-A600 Series Camera Software (v. 3.1, PixeLINK, Ottawa, Ontario, Canada). Sperm motility from each male was assessed at approximately $3.2,32$, and $100 \mathrm{~min}$ subsequent to the copper spike, for each of the seven treatments.

Sperm velocity was measured using a CEROS (v.12) video sperm analysis system (Hamilton-Thorne Research, Beverly, Maine, USA). Only those spermatozoa whose forward movement was recorded for at least $0.33 \mathrm{~s}$ ( $\geq 20$ frames) were analyzed (see Lahnsteiner et al., 1998; Burness et al., 2004 for a similar criterion). The median sperm smooth path velocity (VAP) was calculated for all spermatozoa recorded at each time period (number of sperm recorded, mean \pm SE: $23.9 \pm 1.6$ cells per time period; range: 1-222).
In addition, seven $1 \mathrm{~mL}$ samples of the sperm/water mixture from each male, representing each of the seven treatments, were placed in a $1.5 \mathrm{~mL}$ Eppendor ${ }^{\circledR}$ tube and preserved by adding $500 \mu \mathrm{l}$ of buffered formalin. A $10 \mu \mathrm{L}$ sub-sample from each treatment was placed under a cover slip on a glass slide, and sperm morphology was examined under $400 \times$ magnification. The first ten clear spermatozoa observed from each male were photographed using a PixeLINK Megapixel PL-A662 digital camera mounted on the microscope. Tail lengths were measured using NIH ImageJ software (available at http://rsb.info.nih.gov/ $\mathrm{ij} /$ ), by tracing a freehand line over the tail using an Intuos graphic tablet (Wacom Co. Ltd., Japan), measuring from the centre of the sperm head to the end of the tail to the nearest $0.1 \mu \mathrm{m}$ (see Balshine et al., 2001 for additional details). For all seven treatments, tail lengths were analyzed using a mean value from the 10 photos for each male.

The same experimental treatments were used to assess fertilization success. In this phase of the experiment, our aim was to assess the fertilizing ability of sperm that had been exposed to varying copper concentrations, and not to assess how fertilization proceeds in copper-polluted seawater. Therefore, prior to fertilization trials, we removed aqueous copper from the sperm/ water mixture by performing two water changes. Following the 100 -min recording of sperm velocity, $1 \mathrm{~mL}$ of the sperm/water solution from each of the seven treatments per male was placed in $1.5 \mathrm{~mL}$ Eppendorf ${ }^{\circledR}$ tubes and centrifuged for $10 \mathrm{~min}$ at $14,000 \mathrm{G}$, forming a pellet of sperm at the bottom of the tube. A $900 \mu \mathrm{L}$ aliquot of the supernatant was decanted and replaced with filtered seawater. This procedure was repeated twice. The sperm/water solution was then used in the fertilization success trials (see below). Centrifuging the sperm/water solution did not adversely effect sperm viability, as preliminary trials demonstrated that sperm exhibited comparable motility after centrifuging, and were able to successfully fertilize eggs (see Results; Earnshaw et al., 1986).

To control for variability between and among males and females used in the experiments, fertilization success trials were conducted by mixing sperm from a single male (from each of the seven treatments) with eggs from a single female. The experiment was repeated 7 times with different individuals at each concentration. The female was placed in an isolated container of $250 \mathrm{~mL}$ filtered seawater once she began to release eggs (as was done for the males). Once egg release was complete (approximately 1-2 h), the female was removed, and $125 \mathrm{~mL}$ of water was decanted from the container, leaving a $125 \mathrm{~mL}$ egg/water solution. The egg/water mixture was gently stirred, and $9 \mathrm{~mL}$ of this mixture was added to 7 scintillation vials, representing the control and six copper treatments. One milliliter of the centrifuged sperm/water solution from a single male was added to the egg solution and gametes were allowed to interact in an aerated vial for $1 \mathrm{~h}$, at which point $0.5 \mathrm{~mL}$ of buffered formalin was added to arrest fertilization and preserve developing embryos. Fertilization rate was determined by counting the ratio of fertilized/unfertilized eggs from a randomly selected subsample of at least 100 eggs (range 100152). Fertilized eggs, which exhibit a characteristic polar body, are clearly visible under $200 \times$ magnification. 


\subsection{Experiment 2: Effects of copper on egg viability}

To assess the impact of copper on egg viability, we exposed eggs to varying copper concentrations and then added sperm. Following the onset of gamete release in the water bath, females $(n=8)$ were placed in a beaker containing $70 \mathrm{~mL}$ of filtered seawater and allowed to release eggs for approximately $15 \mathrm{~min}$. The female was then removed from the beaker, and the egg/ water solution was gently stirred to homogenize the solution. Nine milliliter of the egg/water solution were added to each of seven $15 \mathrm{~mL}$ scintillation vials, and the egg/water solution was spiked with $1 \mathrm{~mL}$ of seawater (control) or a copper solution at a concentration 10-fold higher than the desired concentration, to yield the six copper concentrations used in the experiment. To facilitate comparison with the results from Experiment 1, in each treatment (i.e., control and six copper solutions) the egg/ water solutions were held on ice for $100 \mathrm{~min}$ prior to fertilization success trials.

As in Experiment 1, our aim was to assess the fertilizing ability of eggs that had been exposed to varying copper concentrations. Following $100 \mathrm{~min}$ of copper exposure, in each scintillation vial, $8 \mathrm{~mL}$ of the egg/water solution was decanted and replaced with $7 \mathrm{~mL}$ filtered seawater $\left(\sim 11^{\circ} \mathrm{C}\right)$ and a $1 \mathrm{~mL}$ sperm/water solution (which was previously kept on ice). The sperm used in this study were kept in filtered seawater held on ice and were not previously exposed to any of the copper treatments. In all cases, sperm from a single male was used to fertilize the eggs from a single female, to control for variability between and among males and females used in the experiments. The experiment was repeated 8 times with different individuals at each concentration. The sperm/egg mixtures were allowed to interact for $1 \mathrm{~h}$ prior to the addition of $0.5 \mathrm{~mL}$ buffered formalin. Fertilization rates were determined as described above.

\subsection{Experiment 3: Effects of copper on embryo development}

Blue mussel embryo survival was assessed using a wellestablished protocol (NIWA, 2005). As described above, once the mussels began releasing gametes, they were removed from the water bath and placed in individual $250 \mathrm{~mL}$ beakers with $200 \mathrm{~mL}$ filtered seawater. Gamete quality was assessed visually under a microscope at $200 \times$ magnification; individuals were only used if females were shedding round, non-transparent eggs and males were releasing motile sperm. Eggs from 3-4 females were pooled, mixed by gentle stirring, and sieved through a 250- $\mu \mathrm{m}$ mesh into a beaker. Sperm from 2-3 males were pooled in a $1 \mathrm{~L}$ beaker and homogenized by gentle stirring. Eggs were placed in filtered, aerated seawater in a $1 \mathrm{~L}$ beaker and a $10 \mathrm{~mL}$ sperm/water solution was added to achieve fertilization. A random $100 \mu \mathrm{L}$ subsample of egg/sperm mixture was assessed periodically until the total number of fertilized eggs (as evident by the existence of a polar body) equaled or exceeded $80 \%$ of the eggs counted.

The effects of copper toxicity on development were assessed by placing $100 \mu \mathrm{L}$ of the egg solution into seven $15 \mathrm{~mL}$ scintillation vials containing $10 \mathrm{~mL}$ of filtered seawater of each treatment (i.e., control and six copper solutions). This was repeated, resulting in five replicates. Developing embryos in the vials were incubated at $20^{\circ} \mathrm{C}$ for $48 \mathrm{~h}$, after which time $1 \mathrm{~mL}$ buffered formalin was added to arrest development and preserve the embryos. After incubation and preservation, $8 \mathrm{~mL}$ of solution was decanted off and the eggs in the remaining $2 \mathrm{~mL}$ were transferred to a Sedgewick-Rafter counting chamber, where embryo development was scored on the first $100 \mathrm{em}$ bryos randomly observed, under $100 \times$ magnification. Normal embryo development results in the formation of a characteristic ' $\mathrm{D}$ ' shaped mantle; these embryos were considered normal. Embryos not characterized by a clear ' $\mathrm{D}$ ' shaped mantle were considered abnormal.

\subsection{Data analyses}

Data are expressed as means \pm 1 standard error of the mean (SEM) $(n)$ where $n$ represents the number of individual mussels tested. Statistical analyses were performed using the programs JMP (version 5.1, SAS Institute Inc., 2004) and StatView 4.0 (SAS Institute Inc., 1992-1998). Data were first tested for normality using a Shapiro-Wilk test, transformed when necessary to improve the fit to normality, and analyzed using parametric statistics. In cases where data were not normally distributed, non-parametric statistics were used, with all rank data corrected for ties. Analyses of variance (ANOVAs) were followed by a Tukey's HSD post-hoc test. Non-parametric posthoc tests were calculated without using computer software (Siegel and Castellan, 1989).

Sperm swimming speed (VAP $=$ smooth path velocity) data were $\log _{10}$ transformed and examined with repeated-measures ANOVA. To avoid pseudoreplication, all statistical analyses of sperm characteristics were performed by collapsing data collected from each male into a single median (smooth path velocity) or mean value (other parameters) for each male at each time period sampled. As percentage data commonly form a binomial, rather than a normal, distribution, all percentage data (e.g., fertilization success and the percentage of abnormallydeveloped embryos) were arcsine-square root transformed prior to statistical analysis (see Zar, 1999). The influence of copper on fertilization success (using sperm and eggs, respectively) was examined using Friedman's tests (a non-parametric repeatedmeasures ANOVA; Zar, 1999).

\section{Results}

\subsection{Copper analyses}

Background copper levels measured in seawater were less than $1.5 \mu \mathrm{g} / \mathrm{L}$, confirming that tests were done in a pristine area. Nominal concentrations have been used to describe our results. Measured copper concentrations for each of the nominal exposure values are presented in Table 1; the first two experimental concentrations were not significantly different from this background. Following the washing and centrifugation of eggs and sperm, water samples from all treatments yielded copper concentrations less than $2.5 \mu \mathrm{g} / \mathrm{L}$, indicating very little carry-over into the fertilization trials. 

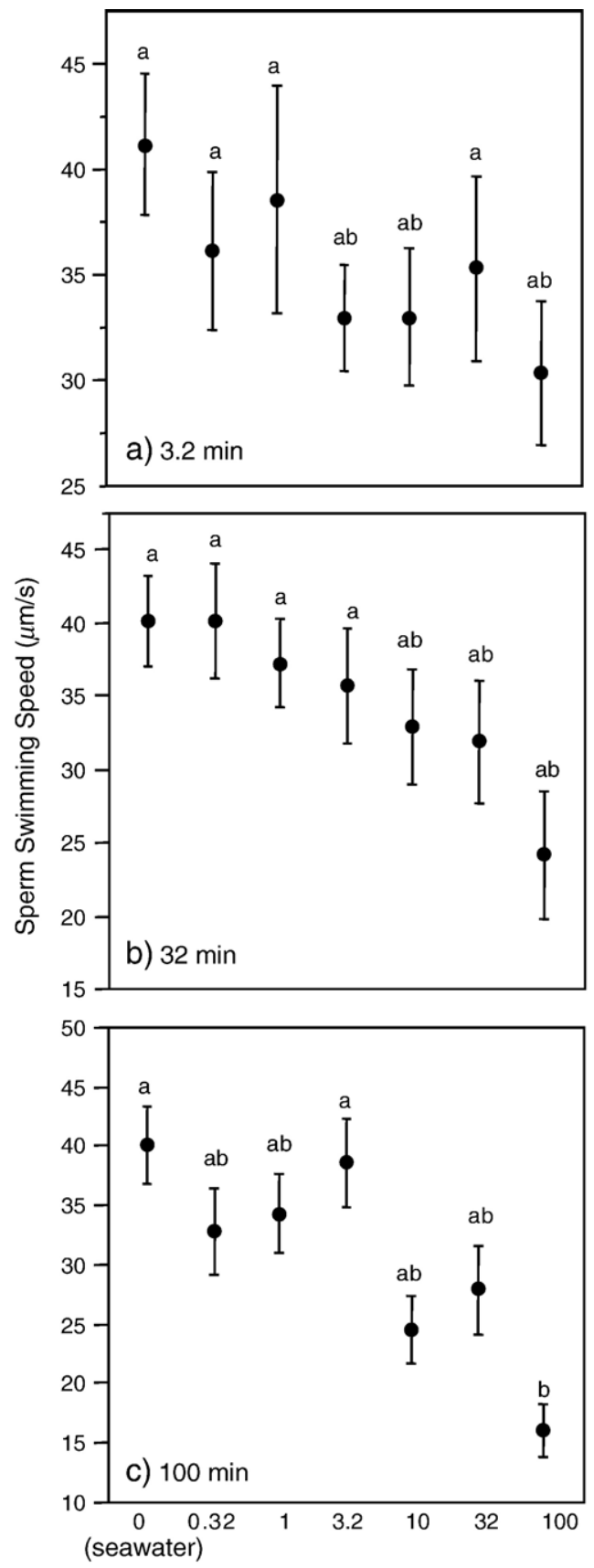

Copper Concentration $(\mu \mathrm{g} / \mathrm{L})$

Fig. 1. Medians $\pm \operatorname{SE}(n=11)$ sperm swimming speed after exposure to increasing copper concentrations for a) 3.2, b) 32 and c) 100 min. Significant differences are indicated with different letters as determined by a Tukey's HSD test following a repeated-measures ANOVA.

\subsection{Experiment 1: Effects of copper on sperm motility and fertilization success}

Sperm swimming speeds varied significantly among treatments, specifically, swimming more slowly when exposed to higher concentrations of copper (repeated-measures ANOVA; $F=4.72, p=0.003$ ). The effects of copper on sperm were only obvious when both the copper concentration and the sperm exposure duration increased. At 3.2 and 32 min after copper exposure, sperm swimming speeds were similar to those observed in controls (Fig. 1a, b). However, sperm exposed to $100 \mu \mathrm{g} / \mathrm{L}$ copper for $100 \mathrm{~min}$ swam significantly slower than sperm swimming in unamended seawater (Fig. 1c).

There was little variation in sperm length (i.e., mean sperm length $=21.81 \pm 0.08$, range: $20.35-23.37 \mu \mathrm{m}$ ) among treatments of varying copper concentrations (ANOVA; $F=0.67, p=0.67$ ). This result suggests that copper does not alter sperm tail morphology and that the effects of copper observed on sperm velocity (see above) were not caused by morphological changes. Furthermore, incorporating mean sperm length as a covariate into the repeated-measures ANOVA examining sperm velocity did not reveal a correlation between sperm length and sperm swimming speed $(F=0.07, p=0.27)$.

Sperm fertilizing capabilities were impaired by exposure to high levels of copper (Freidman's test; $\chi^{2}=19.3, p=0.003$; Fig. 2a). Exposure to the $100 \mu \mathrm{g} / \mathrm{L}$ copper treatment significantly reduced the fertilizing ability of sperm compared to

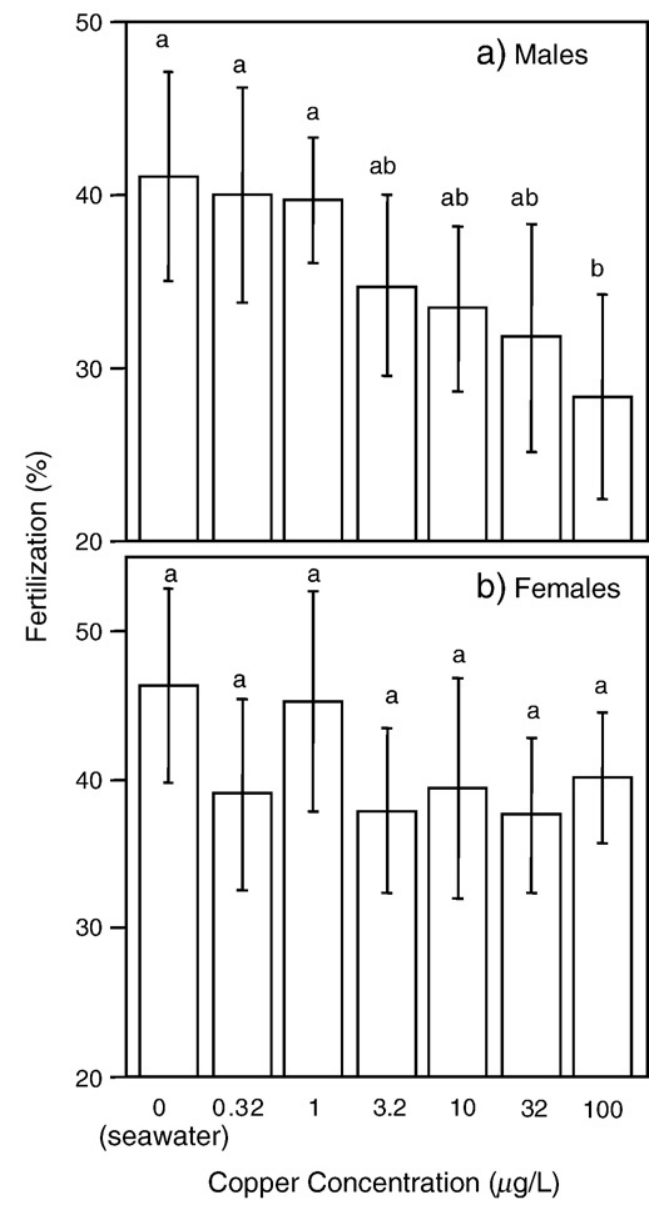

Fig. 2. Fertilization rate of a) males whose sperm were exposed to increasing copper concentrations for 100 min prior to mixing with unexposed eggs and b) females whose eggs were exposed to increasing copper concentrations for $100 \mathrm{~min}$ prior to mixing with unexposed sperm. Gametes were allowed to mix in aerated vials for $1 \mathrm{~h}$ before fertilization was arrested. The percentage of eggs fertilized in a) and b) were determined by counting approximately 100 randomly-sampled eggs. Data are presented as means \pm SE (males $n=7$, females $n=8$ ) and significant differences in mean values are indicated with different letters. 


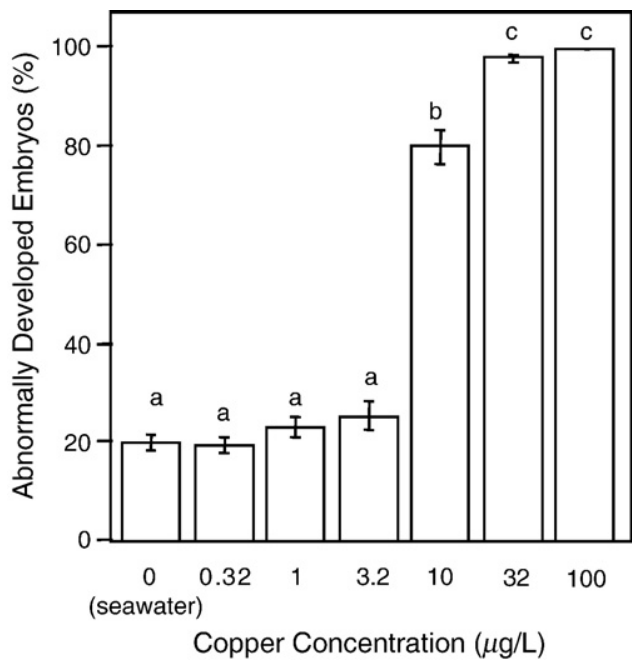

Fig. 3. The percentage of abnormally-developed embryos following exposure to increasing copper concentrations for $48 \mathrm{~h}$. Means $\pm \operatorname{SE}(n=5)$ are presented and different letters indicates differences between copper concentrations.

fertilization capabilities of sperm kept in unamended seawater, or in $0.32 \mu \mathrm{g} / \mathrm{L}$ and $1 \mu \mathrm{g} / \mathrm{L}$ copper treatments.

\subsection{Experiment 2: effects of copper on egg viability}

Increasing concentrations of copper did not influence egg viability, as there were no differences in the percentage of eggs ertilized among the various treatments $\left(\chi^{2}=8.8, p=0.18\right.$, Fig. 2b).

\subsection{Experiment 3: effects of copper on embryo development}

Embryos exposed to high copper concentrations exhibited significantly greater abnormalities than embryos exposed to low concentrations $(F=277.8, p<0.001$; Fig. 3). Embryos developed in unamended seawater (i.e., controls) exhibited $20 \pm 3.5 \%$ abnormal embryos, and a similar proportion of abnormal embryos were observed in the $0.32,1.0$, and $3.2 \mu \mathrm{g} / \mathrm{L}$ copper solutions. The number of embryos with abnormal development was dramatically higher (i.e., a 4-fold increase relative to seawater controls) in the $10 \mu \mathrm{g} / \mathrm{L}$ copper treatment. The number of abnormally-developed embryos was highest at concentrations of 32 and $100 \mu \mathrm{g} / \mathrm{L}$ copper; in the latter concentration (i.e., $100 \mu \mathrm{g} / \mathrm{L}$ copper), all embryos exhibited abnormal development (Fig. 3).

\section{Discussion}

The results of this study demonstrate that exposure of blue mussel sperm and embryos to copper reduce fertilization success at concentrations consistent with those observed at heavilypolluted harbours (e.g., Haynes and Loong, 2002; Soegianto et al., 1999). Thus, by using video tracking and computer-assisted analysis we found that sperm were considerably more sensitive to the adverse effects of copper in this study than in previous work where sperm motility was measured spectrophotometrically (Earnshaw et al., 1986). Notably, Earnshaw et al. (1986) demonstrated a reduction in sperm motility at copper concentrations that exceeded environmentally relevant levels by approximately 100-3000 times (range 6300-208,000 $\mu \mathrm{g} / \mathrm{L}$ ). However, the observed adverse effects of copper on blue mussel sperm in the present study occurred only at concentrations approximately an order of magnitude higher than those causing adverse effects in developing embryos. Embryos demonstrated a dramatic increase in abnormal development between the 3.2 and $10 \mu \mathrm{g} / \mathrm{L}$ copper treatments, considerably lower than the $100 \mu \mathrm{g} / \mathrm{L}$ that results in a decrease in sperm swimming speed and fertilization success. Therefore, as demonstrated in previous studies with other species of marine invertebrates (Ringwood, 1992; Dinnel et al., 1987; Geffard et al., 2001; Novelli et al., 2003), blue mussel embryotoxicity tests were more sensitive in measuring the effects of copper toxicity than blue mussel spermiotoxicity tests. Developing embryos are metabolically active, and slight alterations in enzyme activity can reduce survival. Embryos of species from the genus Mytilus are more sensitive to copper exposure than other marine invertebrates (Arnold et al., 2005). Present US EPA guidelines for copper exposures in seawater are calculated by factoring a "Final Acute Value" of $9.625 \mu \mathrm{g} / \mathrm{L}$ (by 2 for the acute criterion, and by 3.127 for the chronic criterion, US EPA, 1995a). This "Final Acute Value" is based on the genus mean acute value for Mytilus, using EC50 values from 48-hr embryo-larval tests (US EPA, 1995b). The data from this study (i.e., Fig. 3) are in good agreement with this value. Indeed the ecotoxicological results from this study confirm the importance of the 48-hr EC50 embryo-larval development test (US EPA, 1995a) in assessing the effects of copper on recruitment after 48-hr exposure.

Sperm swimming speed and fertilization rates of copperexposed sperm were more sensitive endpoints than egg viability endpoints. In this study, exposing eggs to increasing copper concentrations did not influence fertilization success. This is consistent with previous studies on other marine invertebrates, in which acute exposure of eggs to copper and silver had no effect on fertility (surf clam, Spisula solidissima, Eyster and Morse, 1984; polychaete, Galeolaria caespitosa, Hollows et al., 2007). Therefore, prior to fertilization, eggs are generally relatively insensitive to acute exposures to metals. These results suggest that temporary increases in metal concentrations, that may result from, for example, the introduction of a pollutant from a point source, will not reduce the fertilization capacity of eggs prior to fertilization. However, immediately following fertilization, eggs become metabolically active, exhibiting dramatic changes in membrane ion permeability (Franchet et al., 1997). Copper accumulation into the egg may not be possible prior to fertilization, and therefore, the adverse effects of copper may only be possible subsequent to fertilization.

The sensitivity of blue mussel sperm to copper increased with both copper concentration and exposure time. Sperm exposed to the highest copper concentrations (nominally, $100 \mu \mathrm{g} / \mathrm{L}$ ), for the longest time period measured (i.e., $100 \mathrm{~min}$ ), swam more slowly and exhibited reduced fertilization capacity than control sperm swimming in seawater. Our results are consistent with the conclusions of previous studies examining how metals influence sperm functions, which demonstrated a reduction in sperm 
swimming speed following exposure of sperm to $1-1000 \mu \mathrm{g} / \mathrm{L}$ mercury (goldfish, Carassius auratus, Van Look and Kime, 2003; African catfish, Clarias gariepinus, Rurangwa et al., 1998; sea bass, Dicentrarchus labrax, Abascal et al., 2007), 1000-100,000 $\mu \mathrm{g} / \mathrm{L}$ cadmium (sea urchin, Anthocidaris crassispina, Au et al., 2000; African catfish, Kime et al., 1996), and $2000 \mathrm{mg} / \mathrm{L}$ zinc (African catfish, Kime et al., 1996). Yet by demonstrating that copper reduces sperm swimming speed in blue mussels, our results are at odds with those of other externally-fertilizing fishes. For example, a number of previous studies have indicated that copper exposure does not influence sperm velocity (sea bass, Abascal et al., 2007; African catfish, Mocholkiella paynei; chub, Leuciscus cephalus, and burbot, Lota lota, Lahnsteiner et al., 2004) and sperm even swam faster than corresponding control treatments in the brown trout (Salmo trutta fario, Lahnsteiner et al., 2004). Blue mussel sperm continues swimming for several hours ( $>4 \mathrm{~h}$, personal obs.) while in fishes, particularly freshwater species, sperm are generally short lived (e.g. Ginsberg, 1963). Given the time-dependent nature of the effects of copper on sperm swimming speed these differences in the duration of sperm motility likely account for the opposing results observed when examining how copper influences sperm swimming speed in the freshwater fish species studied to date and the marine invertebrate described in this study.

Reduced sperm swimming speeds are often associated with alterations of sperm morphology. For example, exposure of blue mussel (Mytilus edulis) sperm to much higher copper levels (6300-208,000 $\mu \mathrm{g} / \mathrm{L}$ ) caused mitochondrial damage (Earnshaw et al., 1986), while in sea urchins, sperm exhibited swelling of the midpiece, mitochondrial damage, and breakage of the flagella subsequent to exposure to $>5 \mathrm{mg} / \mathrm{L}$ cadmium (Au et al., $2000,2001 \mathrm{~b}$ ), and in goldfish, exposure to $100 \mathrm{mg} / \mathrm{L}$ mercury reduced sperm flagellar length (Van Look and Kime, 2003). However, the reduction in sperm swimming speed observed in this study occurred at much lower metal levels and does not appear to be the result of copper-induced changes in sperm tail length. Similarly, previous studies did not detect dramatic alterations in sperm morphology following cadmium exposure in the green-lipped mussel (Au et al., 2000). Therefore, it is possible that the impaired sperm function in mussels may be due to physiological, rather than morphological, damage. In particular, we think it likely that exposure of blue mussel sperm to copper interferes with mitochondrial activity, as copper exposure, albeit at higher concentrations, has been earlier shown to reduce the respiration rates of sperm in mussels (Akberali et al., 1985; Earnshaw et al., 1986), which, in turn, reduces sperm swimming speed.

In marine invertebrates, sperm motility is initiated following dilution in seawater, which results in the activation of metabolic pathways necessary to drive the flagella (Rothschild, 1948). Prior to sperm release and activation, sperm are immotile as a result of uncoupled sulfhydryl groups suppressing the activity of cytochrome $\mathrm{C}$, a key enzyme of the electron transport chain (ETC) in the mitochondria that drives energy production (Mohri, 1956). Following sperm release, cytochrome C is released from this inhibition allowing for respiration, which ultimately produces the energy required for the sperm's motility. Once taken up into a cell, copper is reduced to cuprous ions that will readily bind with sulfhydryl groups (Viarengo et al., 1996), and ultimately inhibit ATP production by interfering with electron transport along the ETC (Ay et al., 1999). Furthermore, copper accumulates in sperm mitochondria (Earnshaw et al., 1986), which may decrease mitochondrial membrane potential while causing the formation of reactive oxygen species (ROS), leading to oxidative damage (Krumschnabel et al., 2005). In trout hepatocytes the extent of ROS formation following incubation in $10 \mu \mathrm{M} \mathrm{Cu}$ increased over time, with ROS in exposed cells more than doubling that of controls after $1 \mathrm{~h}$ incubation (Krumschnabel et al., 2005). Therefore, exposure to copper likely interferes with mitochondrial activity, reducing sperm swimming speed. As in the time dependent formations of ROS in trout hepatocytes, the delay in an observed response of sperm swimming speed following copper exposure in this study suggests that spermatozoa are actively respiring, and that copper uptake into the cell (in this case, the gamete cell), and subsequent oxidative damage, are time-dependent. If this hypothesis is correct, male blue mussels may suffer greater reproductive impairment when maintained in environments with chronically-elevated copper concentrations, such as marine harbors, where copper can accumulate in the testes (Kumari et al., 2006) and potentially impair sperm mitochondrial function prior to sperm release.

Chronic effects of metals on reproductive impairment and gametogenesis in marine invertebrates have not been well characterized. However, in polluted marine environments, sexuallymature adults may be chronically exposed to elevated metal concentrations, which can lead to a bioaccumulation of metals in adult tissues. For example, in the short-neck clam (Paphia malabarica) adults living in a polluted estuary exhibited an accumulation of copper in their gonads (Kumari et al., 2006). Furthermore, while Au et al. (2000) demonstrated a timedependent adverse effect of cadmium on sperm motility, subsequent studies by the same authors demonstrated that exposure of mature adults to cadmium for a period of 4 weeks greatly reduced the concentration of cadmium required to impair sperm motility (Au et al., 2001a,b). It remains to be seen if adult blue mussels exposed to chronically-elevated copper concentrations bioaccumulate copper in gonadal tissue. If so, we might expect an intensification of the toxic effects of copper on impairing reproductive function, likely by interfering with mitochondrial activity, as reported by $\mathrm{Au}$ et al. (2001a,b) following chronic cadmium exposure. In particular, reductions in sperm swimming speeds have direct fitness consequences as sperm speed is positively correlated with fertilization success in marine invertebrates (Levitan, 2000), as well as vertebrates (e.g. Gage et al., 2004). Consequently, impaired sperm function subsequent to exposure to metals, together with reduced embryo survival, may magnify any deleterious impacts that metals exert on recruitment in marine environments.

\section{Summary and conclusions}

Acute exposure of blue mussel gametes and embryos to copper impaired sperm motility and reduced fertilization 
success. Eggs were unaffected by copper exposure at all exposure concentrations of copper tested in this study, suggesting that the impaired fertilization rates observed were likely the result of poor sperm function alone. To our knowledge, this study is the first of its kind to demonstrate a reduction in sperm swimming speed in an externally-fertilizing species acutely exposed to copper at environmentally relevant concentrations. This result may be due to the extended duration of sperm motility in blue mussels, which may facilitate time-dependent impacts of copper on mitochondrial function.

\section{Acknowledgments}

We thank the Director and Staff of Bamfield Marine Sciences Centre for their help and cooperation during this study. We also want to especially thank the Research Co-ordinator, Dr. Bruce Cameron, for his assistance during this study and Dr. Robert Montgomerie for kindly providing access to his sperm tracker. We also thank Susan Marsh-Rollo and Julie Desjardins for providing logistical support while in the field, Frédéric Chain for his powerful assistance during data analysis, and Drs. Peter Chapman, Astrid Voigt, and Guy Gilron for constructive criticism. This work was funded by an NSERC (Canada) CRD Grant to CMW, in co-operation with the International Copper Association, the Copper Development Association, the Nickel Producers Environmental Research Association, the International Lead Zinc Research Organization, the International Zinc Association, Noranda-Falconbridge (now Xstrata), Teck Cominco, and Inco, and by a Canadian Foundation for Innovation and Ontario Innovation Trust awarded to SB. JLF and CB are supported by NSERC postgraduate scholarships, and CMW and SB are supported by the Canada Research Chair Program.

\section{References}

Abascal, F.J., Cosson, J., Fauvel, C., 2007. Characterization of sperm motility in sea bass: the effect of heavy metals and physicochemical variables on sperm motility. J. Fish Biol. 70, 509-522.

Akberali, H.B., Earnshaw, M.J., Marriott, K.R.M., 1985. The action of heavy metals on the gametes of the marine mussel, Mytilus edulis (L.)-II. Uptake of copper and zinc and their effect on respiration in the sperm and unfertilized egg. Mar. Environ. Res. 16, 37-59.

Alliot, A., Frenet-Piron, M., 1990. Relationship between metals in seawater and metal accumulation in shrimp. Mar. Pollut. Bull. 32, 471-479.

Apte, S.C., Day, G.M., 1998. Dissolved metal concentration in the Torres Strait and Gulf of Paupa. Mar. Pollut. Bull. 36, 298-304.

Arnold, W.R., 2004. Effects of dissolved organic carbon on copper toxicity: implications for saltwater copper criteria. Integr. Environ. Manag. 1, 34-39.

Arnold, W.R., Santore, R.C., Cotsifas, J.S., 2005. Predicting copper toxicity in estuarine and marine waters using the Biotic Ligand Model. Mar. Pollut. Bull. 50, 1634-1640.

Au, D.W.T., Chiang, M.W.L., Wu, R.S.S., 2000. Effects of cadmium and phenol on motility and ultrastructure of sea urchin and mussel spermatozoa. Arch. Environ. Contam. Toxicol. 38, 455-463.

Au, D.W.T., Lee, C.Y., Chan, K.L., Wu, R.S.S., 2001a. Reproductive impairment of sea urchins upon chronic exposure to cadmium. Part I: effects on gamete quality. Environ. Pollut. 111, 1-9.

Au, D.W.T., Reunov, A.A., Wu, R.S.S., 2001b. Reproductive impairment of sea urchins upon chronic exposure to cadmium. Part II: effects on sperm development. Environ. Pollut. 111, 11-20.
Ay, O., Kalay, M., Tamer, L., Canli, M., 1999. Copper and lead accumulation in tissues of a freshwater fish Tilapia zillii and its effects on the branchial Na, K-ATPase activity. Bull. Environ. Contam. Toxicol. 62, $160-168$.

Balshine, S., Leach, B.J., Neat, F., Werner, N.Y., Montgomerie, R., 2001. Sperm size of African cichlids in relation to sperm competition. Behav. Ecol. 12, $726-731$.

Bellas, J., Vazquez, E., Beiras, R., 2001. Toxicity of $\mathrm{Hg}, \mathrm{Cu}, \mathrm{Cd}$, and $\mathrm{Cr}$ on early developmental stages of Ciona intestinalis (Chordata, Ascidiacea) with potential application in marine water quality assessment. Water Res. 35, 2905-2912.

Bellas, J., Beiras, R., Vazquez, E., 2003. A standardization of Ciona intestinalis (Chordata, Ascidiacea) embryo-larval bioassay for ecotoxicological studies. Water Res. 37, 4613-4622.

Bellas, J., Beiras, R., Vazquez, E., 2004. Sublethal effects of trace metals (Cd, $\mathrm{Cr}, \mathrm{Cu}, \mathrm{Hg}$ ) on embryogenesis and larval settlement of the Ascidian Ciona intestinalis. Arch. Environ. Contam. Toxicol. 46, 61-66.

Bowen, W.J., Engel, D.W., 1996. Effects of protracted cadmium exposure on gametes of the purple sea urchin, Arbacia punctulata. Bull. Environ. Contamin. Toxicol. 56, 493-499.

Burness, G., Casselman, S.J., Schulte-Hostedde, A., Moyes, C., Montgomerie, R., 2004. Sperm swimming speed and energetics vary with sperm competition risk in bluegill (Lepomis macrochirus). Behav. Ecol. Sociobiol. 56, $65-70$.

Davenport, J., Redpath, K.J., 1984. Copper and the mussel Mytilus edulis L. In: Bolis, L., Zadunaisky, J., Gilles, R. (Eds.), Toxins, drugs and pollutants in marine animals. Springer-Verlag, Berlin, pp. 178-189.

Dinnel, P.A., Link, J.M., Stober, Q.J., 1987. Improved methodology for a sea urchin sperm cell bioassay for marine waters. Arch. Environ. Contam. Toxicol. $16,23-32$.

Dinnel, P.A., Link, J.M., Stober, Q.J., Letourneau, M.W., Roberts, W.E., 1989. Comparative sensitivity of sea urchin sperm bioassays to metals and pesticides. Arch. Environ. Contam. Toxicol. 18, 748-755.

Earnshaw, M.J., Wilson, S., Akberali, H.B., Butler, R.D., Marriott, K.R.M., 1986. The actions of heavy metals on the gametes of the marine mussel, Mytilus edulis (L.)-III. The effect of applied copper and zinc on sperm motility in relation to ultrastructure damage and intracellular metal localisation. Mar. Environ. Res. 20, 261-278.

Eyster, L.S., Morse, M.P., 1984. Development of the surf clam (Spisula solidissima) following exposure of gametes, embryos, and larvae to silver. Arch. Environ. Contam. Toxicol. 13, 641-646.

Fernandez, N., Beiras, R., 2001. Combined toxicity of dissolved mercury with copper, lead and cadmium on embryogenesis and early larval growth of the Paracentrotus lividus sea-urchin. Ecotoxicology 10, 263-271.

Franchet, C., Goudeau, M., Goudeau, H., 1997. Mercuric ions impair the fertilization potential, the resumption of meiosis, the formation of the male pronucleus, and increase polyspermy, in the egg of the ascidian Phallusia mammillata. J. Exp. Zool. 278, 255-272.

Gage, M.J.G., Macfarlane, C.P., Yeates, S., Ward, R.G., Searle, J.B., Parker, G.A., 2004. Spermatozoal traits and sperm competition in Atlantic salmon: relative sperm velocity is the primary determinant of fertilization success. Curr. Biol. 14, 44-47.

Geffard, O., Budzinski, H., Augagneur, S., Seaman, M.N.L., His, E., 2001. Assessment of sediment contamination by spermiotoxicity and embryotoxicity bioassays with sea urchins (Paracentrotus lividus) and oysters (Crassostrea gigas). Environ. Toxicol. Chem. 20, 1605-1611.

Ginsberg, A., 1963. Sperm-egg association and its relationship to the activation of the egg in salmonid fishes. J. Embryol. Exp. Morphol. 11, 13-33.

Hall, L.W., Anderson, R.D., 1999. A deterministic ecological risk assessment for copper in European saltwater environments. Mar. Pollut. Bull. 38, 207-218.

Haynes, D., Loong, D., 2002. Antifoulant (butyltin and copper) concentrations in sediment from the Great Barrier Reef World Heritage Area, Australia. Environ. Pollut. 120, 391-396.

His, E., Beiras, R., Seaman, M.N.L., 1999. The assessment of marine pollution bioassays with bivalve embryos and larvae. Adv. Mar. Biol. 37, 1-178.

Hollows, C.F., Johnston, E.L., Marshall, D.J., 2007. Copper reduces fertilization success and exacerbates Allee effects in the field. Mar. Pollut. Bull. 333, $51-60$. 
Katranitsas, A., Castritsi-Catharios, J., Persoone, G., 2003. The effects of a copper-based antifouling paint on mortality and enzymatic activity of a nontarget marine organism. Mar. Pollut. Bull. 46, 1491-1494.

Kime, D.E., Ebrahimi, M., Nesten, K., Roelants, I., Rurangwa, E., Moore, H.D.M., Ollevier, F., 1996. Use of computer assisted sperm analysis (CASA) for monitoring the effects of pollution on sperm quality of fish; application to the effects of heavy metals. Aquat. Toxicol. 36, 223-237.

Krumschnabel, G., Manzl, C., Berger, C., Hofer, B., 2005. Oxidative stress, mitochondrial permeability transition, and cell death in $\mathrm{Cu}$-exposed trout hepatocytes. Toxicol. Appl. Pharmacol. 209, 62-73.

Kumari, L.K., Kaisary, S., Rodrigues, V., 2006. Bio-accumulation of some trace metals in the short-neck clam Paphia malabarica from Mandovi estuary, Goa. Environ. Int. 32, 229-234

Lahnsteiner, F., Weismann, T., Patzner, R.A., 1998. Evaluation of the semen quality of the rainbow trout, Oncorhynchus mykiss, by sperm motility, seminal plasma parameters, and spermatozoal metabolism. Aquaculture 163, 163-181.

Lahnsteiner, F., Mansour, N., Berger, B., 2004. The effect of inorganic and organic pollutants on sperm motility of some freshwater teleosts. J. Fish Biol. 65, 1283-1297.

Levitan, D.R., 2000. Sperm velocity and longevity trade off each other and influence fertilization in the sea urchin Lytechinus variegates. Proc. R. Soc. Lond., B Biol. Sci. 267, 531-534.

Liley, N.R., Tamkee, P., Tsai, R., Hoysak, D.J., 2002. Fertilization dynamics in rainbow trout (Oncorhynchus mykiss): effect of male age, social experience, and sperm concentration and motility on in vitro fertilization. Can. J. Fish Aquat. Sci. 59, 144-152.

Mohri, H., 1956. Studies on the respiration of sea-urchin spermatozoa. II. The cytochrome oxidase activity in relation to the dilution effect. J. Exp. Biol. 33, 330-337.

NIWA, 2005. Standard operating procedure 21.1 blue mussel embryo (Mytilus galloprovincialis) acute toxicity test protocol. National Institute of Water and Atmospheric Research Ltd., Hamilton, New Zealand.

Novelli, A.A., Losso, C., Ghetti, P.F., Ghirardini, A.V., 2003. Toxicity of heavy metals using sperm cell and embryo toxicity bioassays with Paracentrotus lividus (Echinodermata: Echinoidea): comparisons with exposure concentrations in the lagoon of Venice, Italy. Environ. Toxicol. Chem. 22, 1295-1301.

Pagano, G., Esposito, A., Giordano, G.G., 1982. Fertilization and larval development in sea urchins following exposure of gametes and embryos to cadmium. Arch. Environ. Contam. Toxicol. 11, 47-55.

Paulson, A.J., Curl, H.C.J., Feely, R.A., 1989. Estimates of trace metal inputs from non-point sources discharged into estuarines. Mar. Pollut. Bull. 20, 549-555.

Reichelt-Brushett, A.J., Harrison, P.L., 2005. The effects of copper, zinc, and cadmium on fertilization success of gametes from Scleractinian reef corals. Mar. Poll. Bull. 38, 182-187.
Ringwood, A.H., 1992. Comparative sensitivity of gametes and early developmental stages of a sea urchin species (Echinometra mathaei) and a bivalve species (Isognomon californicum) during metal exposures. Arch. Environ. Contam. Toxicol. 22, 288-295.

Rothschild, L., 1948. The physiology of sea urchin spermatozoa. Senescence and the dilution effect. J. Exp. Biol. 25, 353-368.

Rurangwa, E., Roelants, I., Huyskens, G., Ebrahimi, M., Kime, D.E., Ollevier, F., 1998. The minimum effective spermatozoa: egg ratio for artificial insemination and the effects of mercury on sperm motility and fertilization ability in Clarias gariepinus. J. Fish Biol. 53, 402-413.

Siegel, S., Castellan, N.J., 1989. Nonparametric statistics for the behavioral sciences, 2nd ed. McGraw-Hill, New York.

Soegianto, A., Charmantier-Daures, M., Trilles, J.P., Charmantier, G., 1999. Impact of copper on the structure of gills and epipodites of the shrimp Penaeus japonicus (Decapoda). J. Crustac. Biol. 19, 209-223.

Thompson, R.J., 1984. The reproductive cycle and physiological ecology of the mussel Mytilus edulis in a subarctic, non-estuarine environment. Mar. Biol. 79, 277-288.

Thorarinsdottir, G.G., Gunnarsson, K., 2003. Reproductive cycles of Mytilus edulis L. on the west and east coasts of Iceland. Polar Res. 22, 217-223.

Toyota, Y., Okabe, S., Kanamori, S., Kitano, Y., 1982. The determination of Mn, $\mathrm{Fe}, \mathrm{Ni}, \mathrm{Cu}$ and $\mathrm{Zn}$ in seawater by atomic absorption spectrometry after coprecipitation with lanthanum hydroxide. J. Oceanogr. Soc. Jpn. 38, 357-361.

US EPA, 1995a. Short-term methods for estimating the chronic toxicity of effluents and receiving waters to west coast marine and estuarine organisms. US Environmental Protection Agency, Office of Water, Washington, DC, EPA/600/R-95/136.

US EPA, 1995b. Ambient water quality criteria - Saltwater copper addendum. US Environmental Protection Agency, Office of Water, Washington, DC.

Van Look, K.J.W., Kime, D.E., 2003. Automated sperm morphology analysis in fishes: the effect of mercury on goldfish sperm. J. Fish Biol. 63, 1020-1033.

Viarengo, A., 1989. Heavy metals in marine invertebrates: mechanism of regulation and toxicity at the cellular level. Rev. Aquat. Sci. 1, 295-317.

Viarengo, A., Pertica, M., Mancinelli, G., Burlando, G., Canesi, L., Orunesu, M., 1996. In vivo effects of copper on the calcium homeostasis mechanism of mussel gill cell plasma membranes. Comp. Biochem Physiol., C Comp. Pharmacol. 113, 421-425.

White, S.L., Rainbow, P.S., 1985. On the metabolic requirements for copper and zinc in mollusks and crustaceans. Mar. Environ. Res. 16, 215-229.

Xie, Z.C., Wong, N.C., Qian, P.Y., Qiu, J.W., 2005. Responses of polychaete Hydroides elegans life stages to copper stress. Mar. Ecol. Prog. Ser. 285, 89-96.

Zar, J.H., 1999. Biostatistical Anlaysis, 4th ed. Prentice Hall, New Jersey. 